\title{
Intestinal and biliary infection with Ascaris lumbricoides in gastrointestinal endoscopy
}

\author{
L. Julián-Gómez, J. Barrio, C. de la Serna, M. Pérez-Miranda, P. Gil-Simón, S. Gómez de la Cuesta, \\ R. Atienza and A. Caro-Patón
}

Service of Digestive Diseases. Hospital Río Hortega. Valladolid, Spain

\section{CASE REPORT 1}

A 54-year-old female patient with no relevant history underwent colonoscopy for rectal bleeding. An ascaris worm was seen at the appendiceal orifice, which was withdrawn using a polypectomy snare and sent to microbiology for diagnosis confirmation. Treatment consisted of single-dose albendazole.

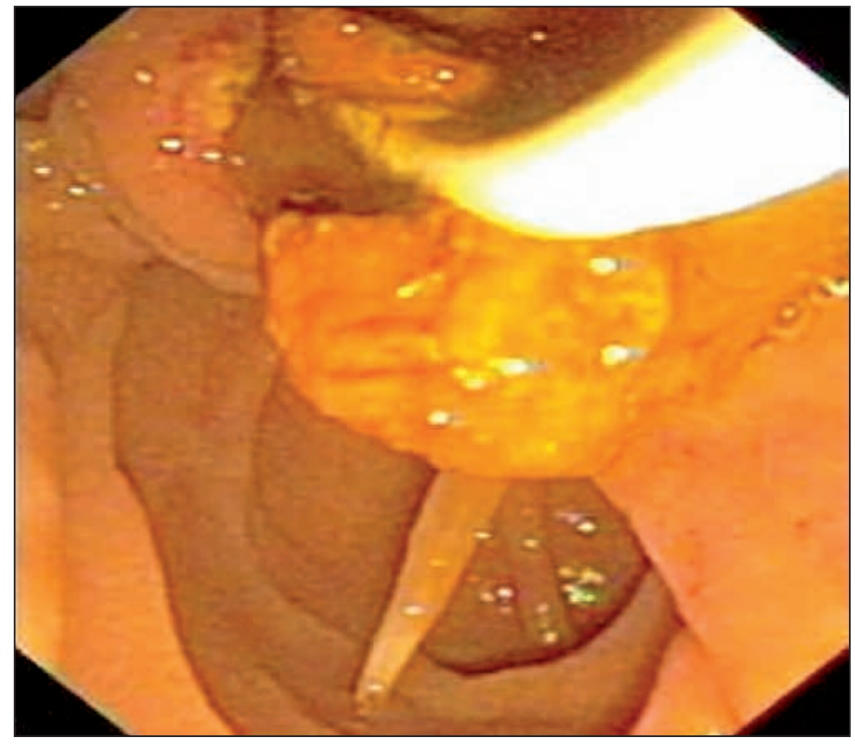

Fig. 1. A. lumbricoides and bile stone removal with a Fogarty balloon. Extracción con balón de Fogarty de A. Lumbricoides y cálculo biliar.

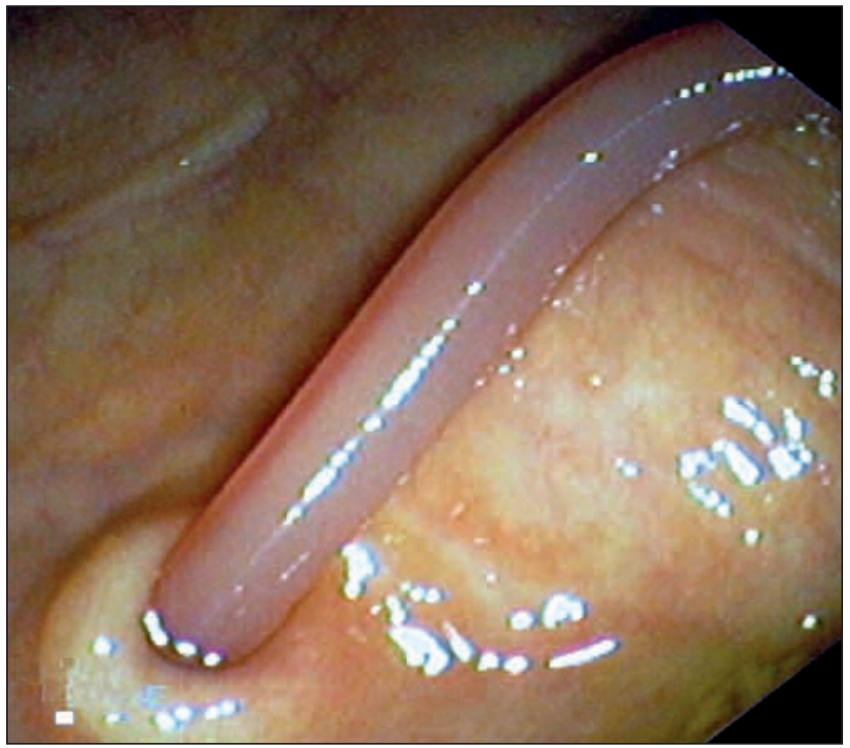

Fig. 2. A. lumbricoides sticking out of the appendiceal orifice. A. Lumbricoides asomando por el orificio apendicular.

\section{CASE REPORT 2}

A female patient was admitted because of epigastric pain radiating to the right hypochondrium, associated with nausea and vomiting, over the past 24 hours. Laboratory tests: leukocytosis $17,500 / \mathrm{mm}^{3}$, polymorphonuclear leukocytes $75 \%$, amylase $1956 \mathrm{U} / \mathrm{L}$, AST: $89 \mathrm{U} / \mathrm{L}$, ALT $120 \mathrm{U} / \mathrm{L}$. Abdominal ultrasounds: dilated extrahepatic bile tract with repletion defects. ERCP: dilated common bile duct with a filiform repletion defect folded onto itself, occupying the entire extrahepatic bile tract. The bile tract was cleared using a Fogarty balloon, and a cylindrical, 23-cm-long worm was withdrawn, together with biliary mud and two bile stones smaller than $10 \mathrm{~cm}$ in size. The bile tract was flushed with saline, and therapy with oral albendazole $400 \mathrm{mg}$ for 4 days was prescribed. The patient was discharged with no symptoms on the $7^{\text {th }}$ day after admission. 


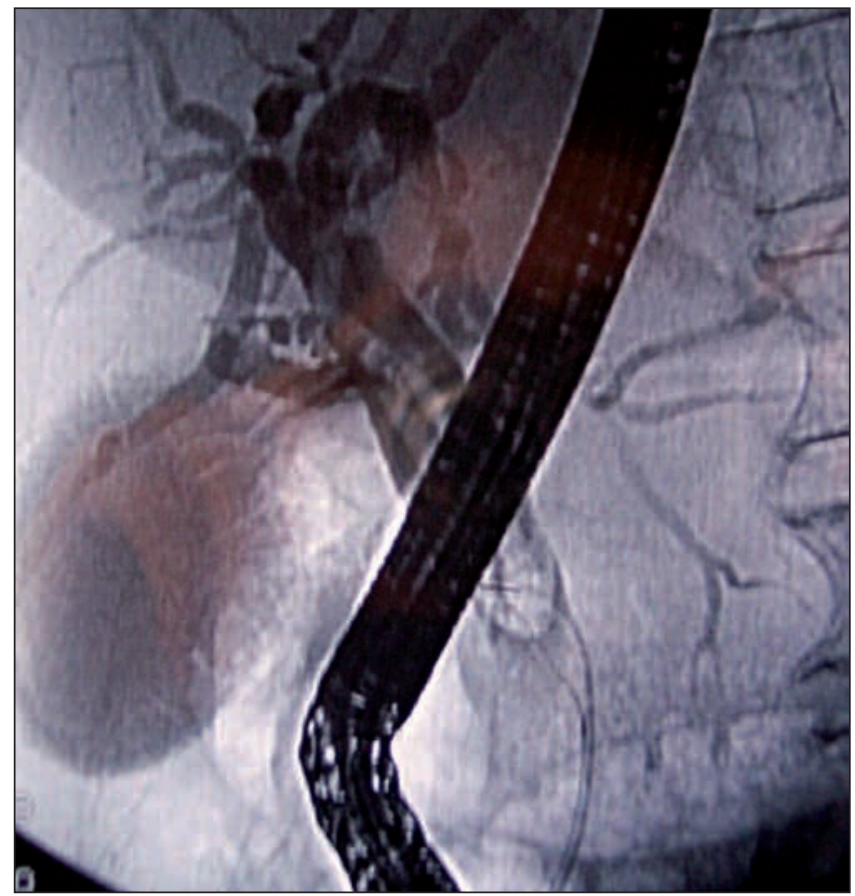

Fig. 3. Main bile duct with a filiform image (A. lumbricoides) inside. Vía biliar principal con imagen filiforme (A. lumbricoides) en su interior.

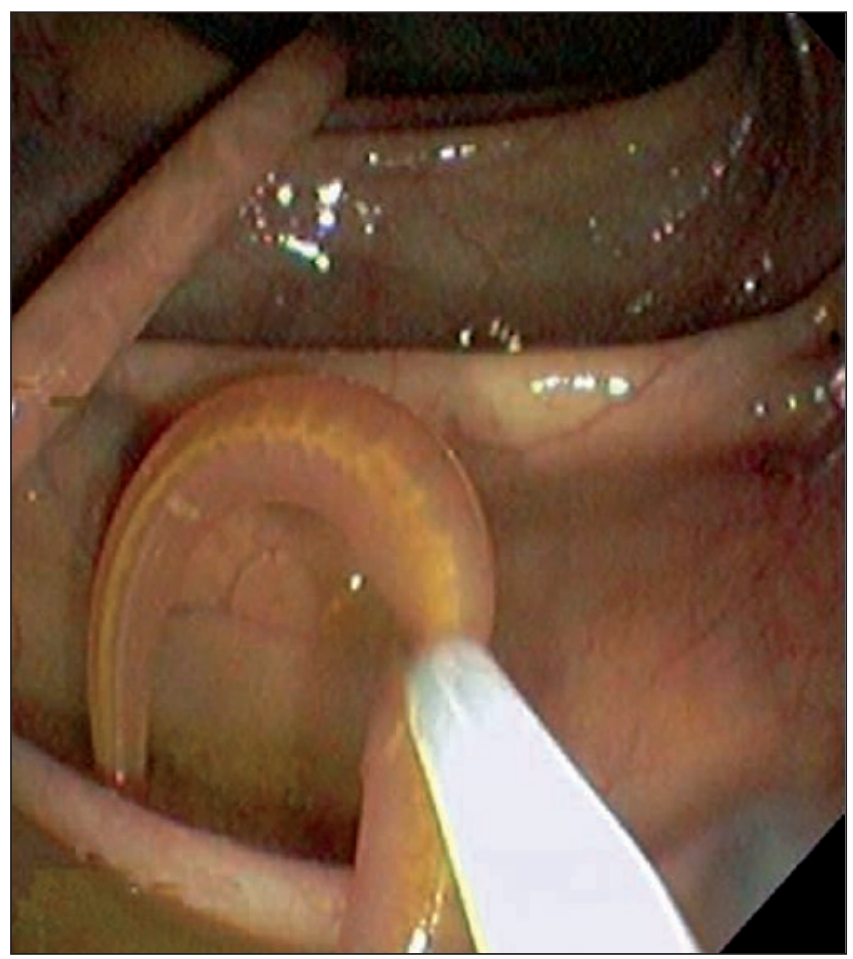

Fig. 4. A. lumbricoides removal from the appendix using a polypectomy snare.

Extracción con asa de polipectomía de A. lumbricoides del apéndice.

\section{DISCUSSION}

Ascaris lumbricoides is the helminth infection that most commonly affects human beings, with a worldwide prevalence of $25 \%$. Transmission ensues from the ingestion of infective eggs. Infection is commonly asymptomatic and may cause nonspecific gastrointestinal complaints and both intestinal (intestinal obstruction from a mass of worms) and extraintestinal (lung, hepatobiliary, neurological) complications. Hepatobiliary involvement with Ascaris is uncommon in our setting, and may result in biliary colic, alithiasic cholecystitis, cholangitis, acute pancreatitis, and liver abscess. Diagnosis results from eggs found in fecal matter or from plain X-ray in intestinal infection or ultrasounds, CT or ERCP in biliary illness. Treatment consists of anti-helminth agents. ERCP is also recommended for helminth removal without sphincterotomy.

\section{RECOMMENDED REFERENCES}

1. Khuroo MS. Ascariasis. Gastroenterol Clin North Am 1996; 25: 553-77.

2. Khuroo MS, Zargar SA, Mahajan R. Hepatobiliary and pancreatic ascariasis in India. Lancet 1990; $335: 1503-6$.

3. Valentine CC, Hoffner RJ, Henderson SO. Three common presentations of ascariasis infection in an urban Emergency Department. J Emerg Med 2001; 20: $135-9$.

4. Cho YD, Kim YS, Cheon YK, Shim CS, Hong SS. Ascaris-induced acute pancreatitis treated endoscopically. Gastrointest Endosc 2007 ; 66: 1226-7. 